\title{
BS7910:2005 FAILURE ASSESSMENT DIAGRAM (FAD) ON CRACKED CIRCULAR HOLLOW SECTION (CHS) WELDED JOINTS
}

\author{
S.T. Lie * and Z.M. Yang \\ School of Civil and Environmental Engineering, Nanyang Technological University \\ 50 Nanyang Avenue, Singapore 639798, Singapore \\ *(Corresponding author: E-mail: cstlie@ntu.edu.sg)
}

Received: 19 March 2008; Revised: 15 July 2008; Accepted: 28 July 2008

\begin{abstract}
The failure assessment diagram (FAD) has been widely accepted for assessing the safety and integrity of cracked and damaged metallic structures. Recently, the usage of this method for offshore structures has been validated extensively and included in the Annex B of BS7910 [1]. However, the recommended equations are valid only for uni-planar circular hollow section (CHS) T, Y, K and KT tubular welded joints. In this paper, an actual assessment has been carried out on cracked (CHS) tubular K-joint containing a surface crack located at the crown location. The fatigue crack depths $a$ and lengths $2 c$ vary from $3.30 \mathrm{~mm}$ to $20.83 \mathrm{~mm}$ and $70.40 \mathrm{~mm}$ to $191.78 \mathrm{~mm}$ respectively. The value of $\beta$, ratio of brace to chord diameter, is 0.52 , which is within the validity range specified in the codes of practice. The recommended correction factor $F_{\mathrm{AR}}$, is used to calculate the plastic collapse load $P_{\mathrm{c}}$, and the usage of BS7910 [1] Level 2A FAD for cracked CHS tubular K-joint is demonstrated accordingly.
\end{abstract}

Keywords: Crack; circular hollow section (CHS); failure assessment diagram (FAD); fracture toughness; $\mathrm{K}$-joint; plastic collapse load; stress intensity factor

\section{INTRODUCTION}

In practice, the safety of any welded structure depends very much on the usage of non-destructive inspection to detect crack before it develops to a critical size, and hence to permit component repair or replacement before catastrophic failure occurs. To determine the critical crack size, the structure should be assessed according to the knowledge of the service stresses and the knowledge of the fracture properties of the material.

Therefore, fracture mechanics is an indispensable tool for performing a critical assessment of a defect discovered in any steel structure. The main objective of this assessment is to establish the maximum tolerable defect size which would not compromise the service requirements. At the design stage, the ability to evaluate the tolerance of a structure to possible defects may be used to optimize the design with respect to properties of the material, geometric shape, and ease of inspection. During operation an assessment may be used to reassess a structure that has been found to contain defects, thus helping in making rational repair or no-repair decisions and improving the inspection strategy.

Recently, American Petroleum Institute API RP579 [2], British Standard BS7910 [1] and Central Electricity Generating Board CEGB R6 [3] procedure give guidance for assessing the acceptability of defects in welded structures based on the failure assessment diagram (FAD) method. The FAD method was originally derived from the original two-criterion approach reported by Dowling and Townley [4]. This approach states that a structure can fail by either of two mechanisms, brittle fracture or plastic collapse, and that these two mechanisms are connected by an interpolation curve based on the strip yield model. If the service (assessment) point falls inside the assessment curve, the structure is considered safe, otherwise, the structure is deemed unsafe. This method enables the 
analyst to go directly from linear elastic fracture mechanics (LEFM) calculations to plastic instability calculations (Wiesner et al. [5]).

The assessment curves specified in the BS7910 [1] are different for different materials and geometries. However, the lower bound curves are always used to assess all types of structures including the cracked circular hollow section (CHS) T, Y, K and KT-joints. In this paper, the standard Level 2A FAD curve is used to assess a typical cracked tubular CHS K-joint specimen. The plastic collapse correction factor $F_{\mathrm{AR}}$, as recommended in Annex B of BS7910 [1], is used to calculate the plastic collapse load $P_{\text {c }}$. Knowing the elastic stress intensity factor $K_{\mathrm{I}}$ and the fracture toughness $K_{\mathrm{IC}}$, the corresponding values of $K_{\mathrm{r}}$ and $L_{\mathrm{r}}$ for different crack sizes are plotted in the FAD curve accordingly. The loading paths are then used to study the fracture assessment sensitivity analysis as the flaw (crack) increases with time.

\section{FAILURE ASSESSMENT DIAGRAM (FAD)}

According to BS7910 [1], any uni-planar cracked tubular CHS T, Y, K and KT-joints can be assessed using the normal assessment route. The standard FAD curve has two curves, namely Level $2 \mathrm{~A}$ and $2 \mathrm{~B}$ as shown in Figure 1 respectively.

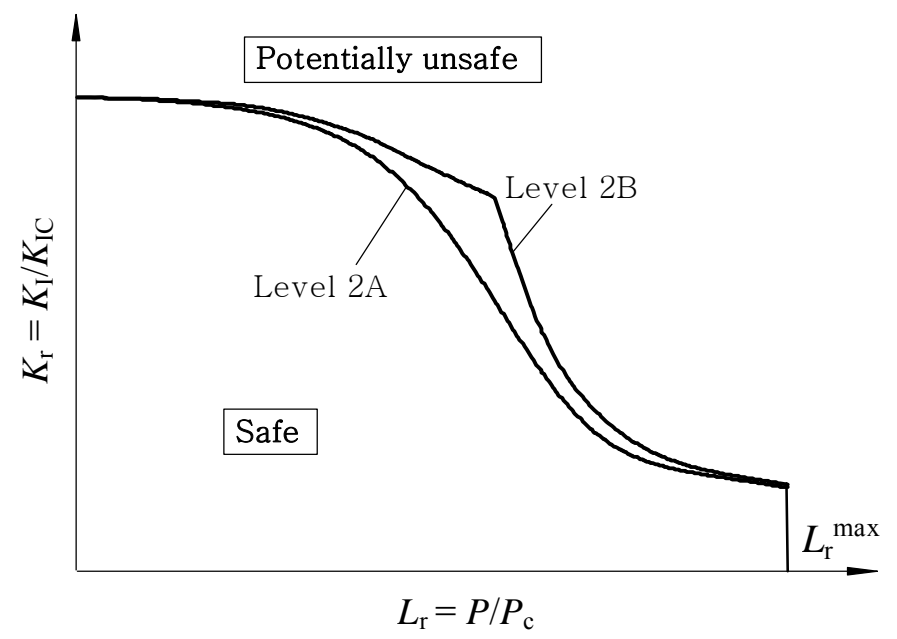

Figure 1. BS7910 [1] Levels 2A and 2B FAD Curves

The Level 2A and 2B curves can be described respectively by the following equations:

$$
K_{\mathrm{r}}=\left(1-0.14 L_{\mathrm{r}}^{2}\right)\left[0.3+0.7 \exp \left(-0.65 L_{\mathrm{r}}^{6}\right)\right]
$$

and

$$
K_{\mathrm{r}}=\left(\frac{E \varepsilon_{\mathrm{ref}}}{L_{\mathrm{r}} \sigma_{\mathrm{Y}}}+\frac{L_{\mathrm{r}}^{3} \sigma_{\mathrm{Y}}}{2 E \varepsilon_{\text {ref }}}\right)^{-\frac{1}{2}}
$$

where $E$ is Young's modulus, $\varepsilon_{\text {ref }}$ is reference strain and $\sigma_{\mathrm{Y}}$ is yield stress of the material, and

$$
K_{\mathrm{r}}=\frac{K_{\mathrm{I}}}{K_{\mathrm{IC}}}
$$


$L_{\mathrm{r}}=\frac{\text { total applied load giving to } \sigma^{\mathrm{P}} \text { stresses }(P)}{\text { plastic collapse load of flawed structure }\left(P_{\mathrm{c}}\right)}$

The application of Level 2B requires the knowledge of a complete stress-strain curve; in particular the region around the yield point has to be available in a detailed manner. However, there are many cases where this information is not available to the users. Therefore, Eq. $1 \mathrm{~b}$ is applied for a number of materials to generate a material independent lower bound curve of Level 2A as shown in Figure 1 , which is the more conservative curve.

As it can be seen, this method adopts the assessment curve which uses the ratio of the stress intensity factor $K_{\mathrm{I}}$ to the fracture toughness $K_{\mathrm{IC}}$, defined as $K_{\mathrm{r}}$ as the vertical (fracture) axis, and the ratio of the applied load $P$ to the plastic collapse load $P_{\mathrm{c}}$, defined as $L_{\mathrm{r}}$ as the horizontal (plasticity) axis. If the service (assessment) point falls inside the assessment curve, the structure is considered safe, otherwise, the structure is deemed unsafe.

It is also important to recognize that the $K_{\mathrm{r}}$ parameter of the assessment diagram uses the linear elastic stress intensity factor with no allowance for the effect of plasticity on the crack tip driving force. As $L_{\mathrm{r}}$ value increases, plasticity also increases the effective crack tip driving force. If it is considered that fracture actually occurs when the total effective crack tip driving force, the elastic plastic value of $J_{\text {ep }}$ reaches a critical value equivalent to the fracture toughness, then this will occur at $\sqrt{E J_{\mathrm{ep}}}=K_{\mathrm{IC}}$. Since the applied linear elastic stress intensity factor is equivalent to $\sqrt{E J_{\mathrm{e}}}$ where $J_{\mathrm{e}}$ is the linear elastic $J$-integral, then

$$
K_{\mathrm{r}}=\frac{K_{\mathrm{I}}}{K_{\mathrm{IC}}}=\sqrt{\frac{J_{\mathrm{e}}}{J_{\mathrm{ep}}}}
$$

As plastic increases so the ratio $\sqrt{J_{\mathrm{e}} / J_{\mathrm{ep}}}$ reduces, and this defines the shape of the assessment curve with the increasing of $L_{\mathrm{r}}$. The standard assessment curve is originally derived for the case of a large plate under tension loading with a central crack (Dawes and Denys [6]). They have been shown to represent a lower bound curves for other common simple geometries.

\section{$2.1 \quad$ Fracture Axis $\mathrm{K}_{\mathrm{r}}$}

For assessing the safety and integrity of an existing cracked structure, the fracture parameter $K_{\mathrm{r}}$ given by Eq. 2 is usually used in practice. The elastic stress intensity factors $K_{\mathrm{I}}$ along the 3D crack front of the K-joint specimen can be obtained from a finite element analysis (Lie et al. [7]), and the material fracture toughness $K_{\mathrm{IC}}$ can be determined from the standard CTOD or $J$ values tests (BS7448-1 [8]). When the joint is subjected under a mixed mode condition, the effective stress intensity factor $K_{\text {eff }}$ should be used to replace the $K_{\mathrm{I}}$ as

$$
K_{\text {eff }}=\sqrt{K_{\mathrm{I}}^{2}+K_{\mathrm{II}}^{2}+K_{\mathrm{III}}^{2} /(1-v)}
$$


where $K_{\mathrm{I}}, K_{\mathrm{II}}, K_{\mathrm{III}}$ are the Mode-I, II and III stress intensity factors respectively, and $v$ is the Poisson's ratio. However, it was shown that the Mode-I stress intensity factors are the dominant ones (Lie et al. [9]), and they are almost equal to $K_{\text {eff }}$ for the K-joint subject under axial (AX) and in-plane bending (IPB) loads shown in Figure 3.

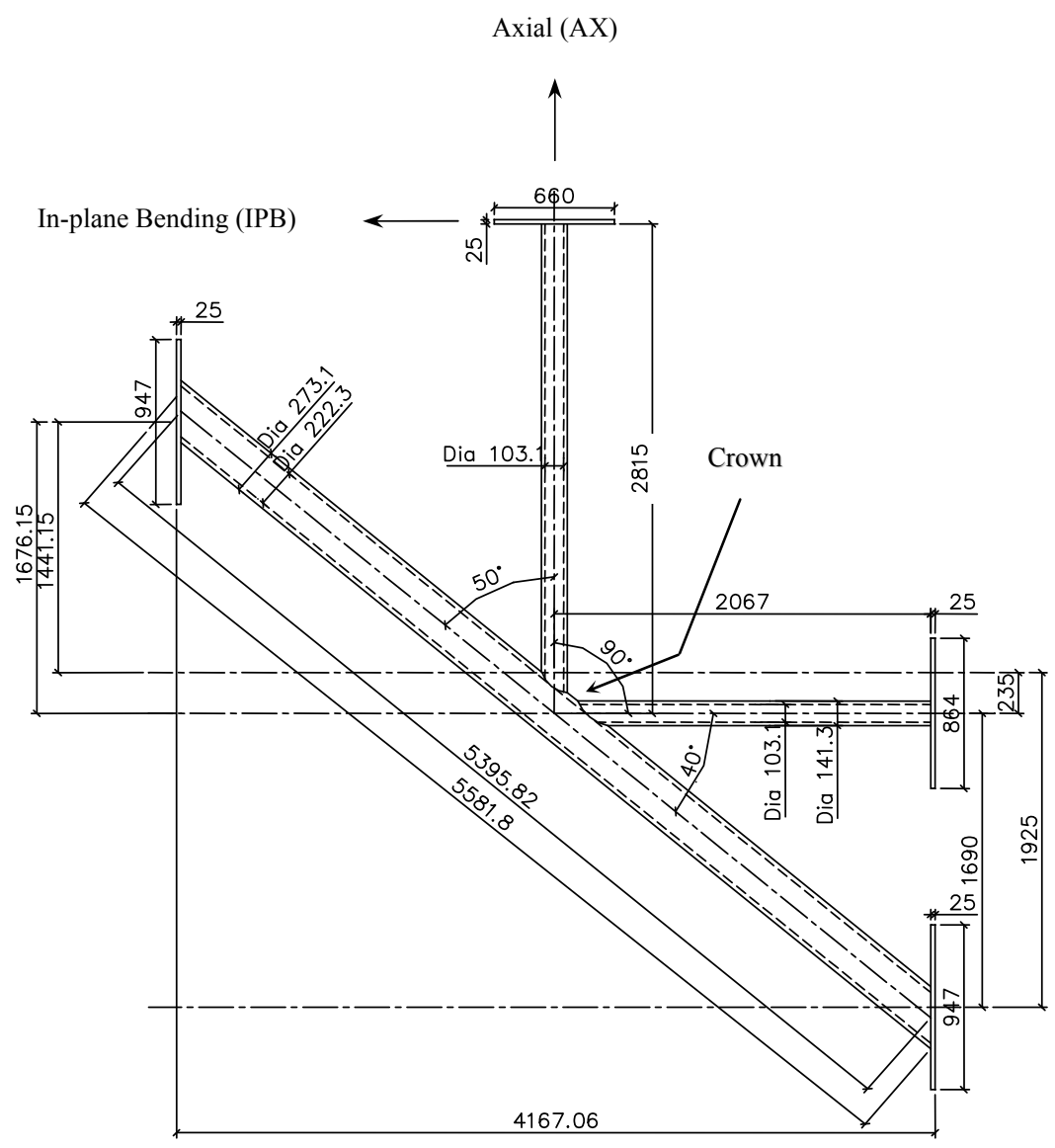

Figure 3. The Full-scale K-joint Specimen

\section{$2.2 \quad$ Plasticity Axis $L_{\mathrm{r}}$}

As it is very difficult to obtain the plastic collapse load of any offshore cracked tubular welded joint, BS7910 [1] has recommended that the plastic collapse load of the cracked geometry $P_{c}$ is determined by reducing the plastic collapse load for the corresponding uncracked geometry $P_{\text {uncracked }}$ using the correction factor $F_{\mathrm{AR}}$. The plastic collapse load of an uncracked K-joint can be obtained from the Health and Safety Executive (HSE) [10]. The correction factor $F_{\mathrm{AR}}$ for axial load is given by

$$
F_{\mathrm{AR}}=\left[1-\frac{\text { cracked area }}{(\text { intersection length } \times T)}\right]\left(\frac{1}{Q_{\beta}}\right)^{m_{\mathrm{q}}}
$$

where $T$ is chord thickness, $Q_{\beta}$ is 1 for $\beta \leq 1.0$ and $m_{\mathrm{q}}$ is 1 for (CHS) tubular K-joints.

For in-plane bending moment, the correction factor $F_{\mathrm{AR}}$ is given by 


$$
F_{\mathrm{AR}}=\cos \left(\frac{\varphi}{2}\right) \cdot\left(1-\sin \left(\frac{\varphi}{2}\right)\right)
$$

where the angle $\varphi$ is defined in Figure 2.

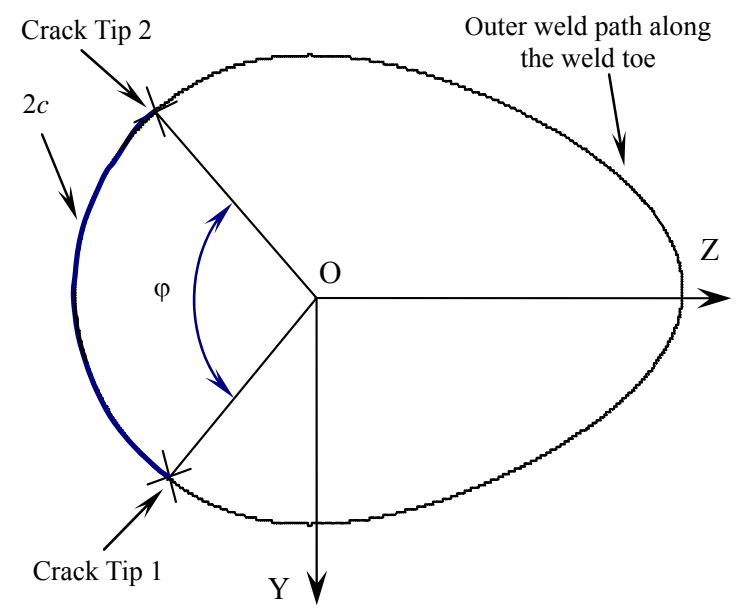

Figure 2. Definition of the Angle $\varphi$ Used in Equation 7

In Annex B of BS7910 [1], the $L_{\mathrm{r}}$ parameter for any tubular joint subjected under combined loads is given by the following equation:

$L_{\mathrm{r}}=\left(\frac{\sigma_{\mathrm{F}}}{\sigma_{\mathrm{Y}}}\right)\left\{\left|\frac{P_{\mathrm{a}}}{P_{\mathrm{c}}}\right|+\left(\frac{M_{\mathrm{ai}}}{M_{\mathrm{ci}}}\right)^{2}+\left(\frac{M_{\mathrm{ao}}}{M_{\mathrm{co}}}\right)\right\}$

where $\sigma_{\mathrm{F}}$ and $\sigma_{\mathrm{Y}}$ are the flow and yield stresses; $P_{\mathrm{a}}, M_{\mathrm{ai}}$ and $M_{\text {ao }}$ are the applied axial load, in-plane bending and out-of-plane bending; and $P_{\mathrm{c}}, M_{\mathrm{ci}}$ and $M_{\mathrm{co}}$ are the plastic collapse load in the cracked condition for axial load, in-plane bending and out-of-plane bending respectively. The plastic collapse load is obtained by reducing the plastic collapse load of the corresponding uncracked geometry on the basis of the net load-bearing area for axial load and the effect of the flaw area on the plastic collapse modulus for bending moments.

\section{FRACTURE ASSESSMENT OF A CRACKED k-JOINT}

\subsection{Specimen Dimensions}

A full-scale cracked tubular K-joint shown in Figure 3 containing fatigue cracks will be assessed in this paper. In the fatigue test carried out earlier (Lie et al. [11]), an axial (AX) and an in-plane bending (IPB) were applied at the brace end. As the hot spot stress was located at the crown of the chord, and the applied loads were symmetrical, the crack was found to initiate and propagate symmetrically from this position.

The notations used to describe the joint parameters, namely $\alpha=2 L / D, \beta=d / D, \gamma=D / 2 T, \tau=t / T$ and $2 \varsigma=g / D$ are given in Figure 4, and the overall dimensions are tabulated in Table 1. 


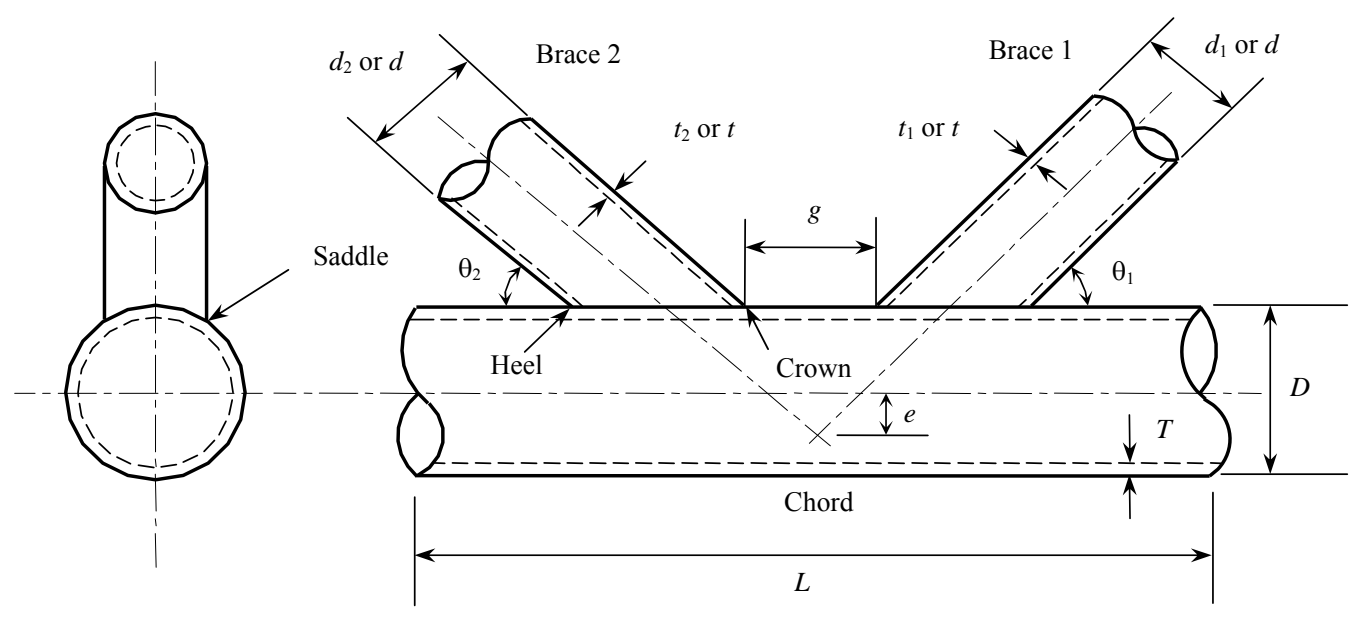

Figure 4. Parameters of the K-joint Specimen

Table 1. Overall Dimensions of the K-joint Specimen

\begin{tabular}{|c|c|c|c|c|c|c|c|c|c|c|c|}
\hline Specimen & $\begin{array}{c}D \\
(\mathrm{~mm})\end{array}$ & $\begin{array}{c}d \\
(\mathrm{~mm})\end{array}$ & $\begin{array}{c}T \\
(\mathrm{~mm})\end{array}$ & $\begin{array}{c}t \\
(\mathrm{~mm})\end{array}$ & $\begin{array}{c}g \\
(\mathrm{~mm})\end{array}$ & $\begin{array}{c}\theta_{1}, \\
\theta_{2}\end{array}$ & $\begin{array}{c}L \\
(\mathrm{~mm})\end{array}$ & $\alpha$ & $\beta$ & $\gamma$ & $\varsigma$ \\
\hline K-joint & 273.1 & 141.3 & 25.4 & 19.1 & 102 & $45^{\circ}$ & 5395.82 & 39.52 & 0.52 & 5.38 & 0.37 \\
\hline
\end{tabular}

To capture the crack details during the earlier test (Lie et al., [11]), an alternating current potential drop (ACPD) technique shown in Figure 5 was used in the fatigue test (Dover et al. [12]). The results showed that the captured crack profile by the ACPD technique agreed quite well with the actual crack shape. It is especially so at the deepest points where the ACPD measurements are capable of providing accurate and useful information such as the stress intensity factors. The measured crack depth $a$ and the corresponding crack length $2 c$ are tabulated in Tables 2 and 3 respectively.

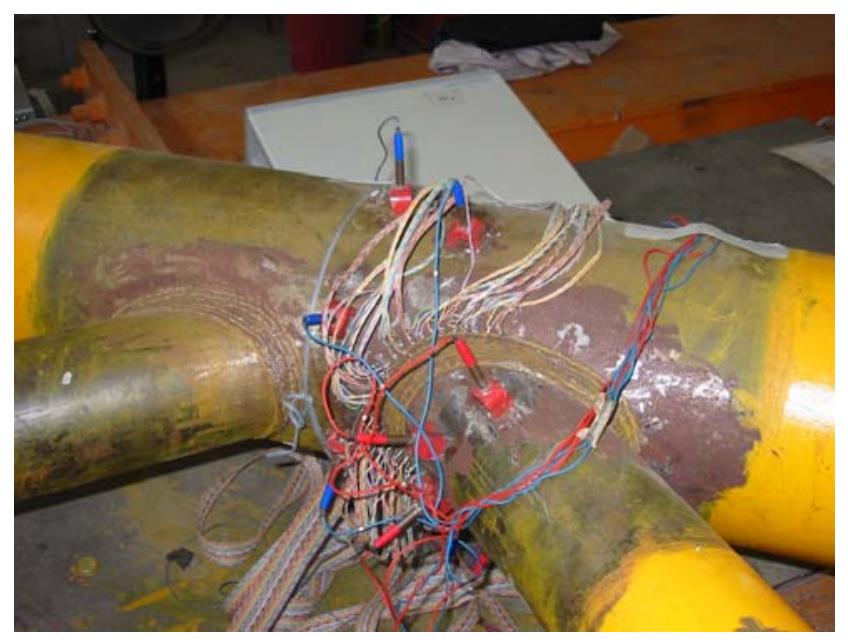

Figure 5. ACPD Test Set-up and Location of the Crack

The crack shapes at different propagation stages were plotted from the ACPD readings, and they were compared with the actual crack shape measured by manual method. The two types of crack shapes were then compared with a semi-elliptical shape having the same depth and length (Figure 6). From the earlier fatigue test (Lie et al. [11]), it can be seen that it is reasonable to assume a semi-elliptical crack shape in the numerical model. 


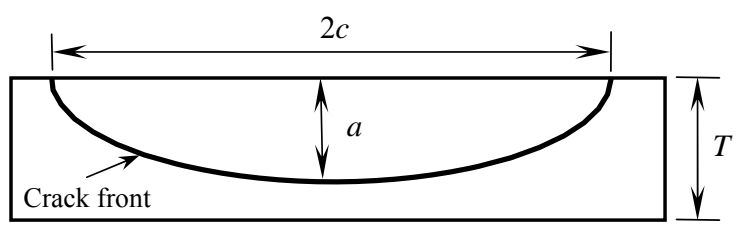

Figure 6. Semi-elliptical 3D Surface Crack

\subsection{Mesh Generation of Cracked K-joint}

To generate the mesh of the completed tubular K-joint model with a surface crack which can be located at any position with any length and depth, five types of elements are used in the present mesh generation procedure. Quarter-point crack tip elements are used along the crack front to simulate the displacements singularity. For these elements, the mid-side nodes are moved to the quarter point for the edge connected to the crack front. Prism elements are employed to model the transition zone between the region near the crack surface and the far field region. Tetrahedral elements are used to link the quarter-point crack tip elements and other types of elements which enclose the crack front. Pyramid elements are used to connect the prism elements with tetrahedral elements around the crack front. In the fields far away from the crack, hexahedral elements are used to model the remaining part of the members. The locations of these different types of elements are illustrated in Figure 7.

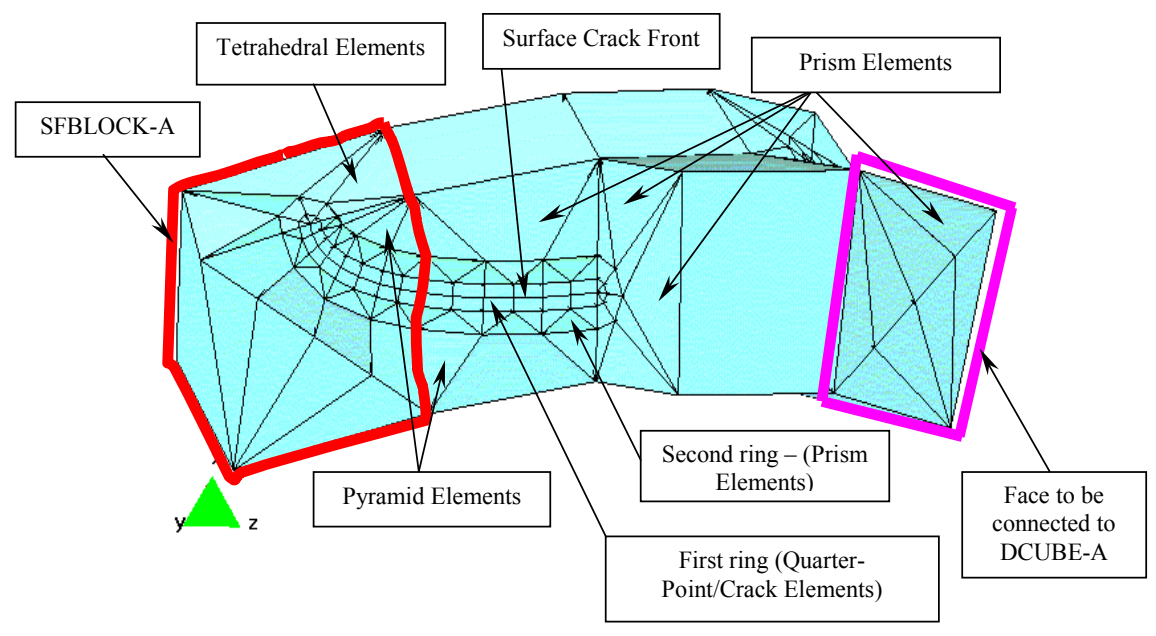

Figure 7. Detailed Mesh Along the Crack Front

In the mesh generation, all the zones are classified into three main types: refined (Zone CF, Zone CF1 and Zone CRBLOCK), coarse zones (Zone A, Zone ER, Zone EL, EXTENCHL, EXTENCHR and Zone H) and transition zones (Zone B, Zone D, Zone G1 and Zone G2) as shown in Figure 8. In the zones with refined mesh, three layers of elements are generated in the thickness direction so as to model the crack depths. The mesh of the surface crack is extracted from Zone CF1. In the coarse mesh zones, only one layer of elements is generated in thickness direction. In the transition zones, Zone B connects Zone A and Zone CF or Zone CF1. 


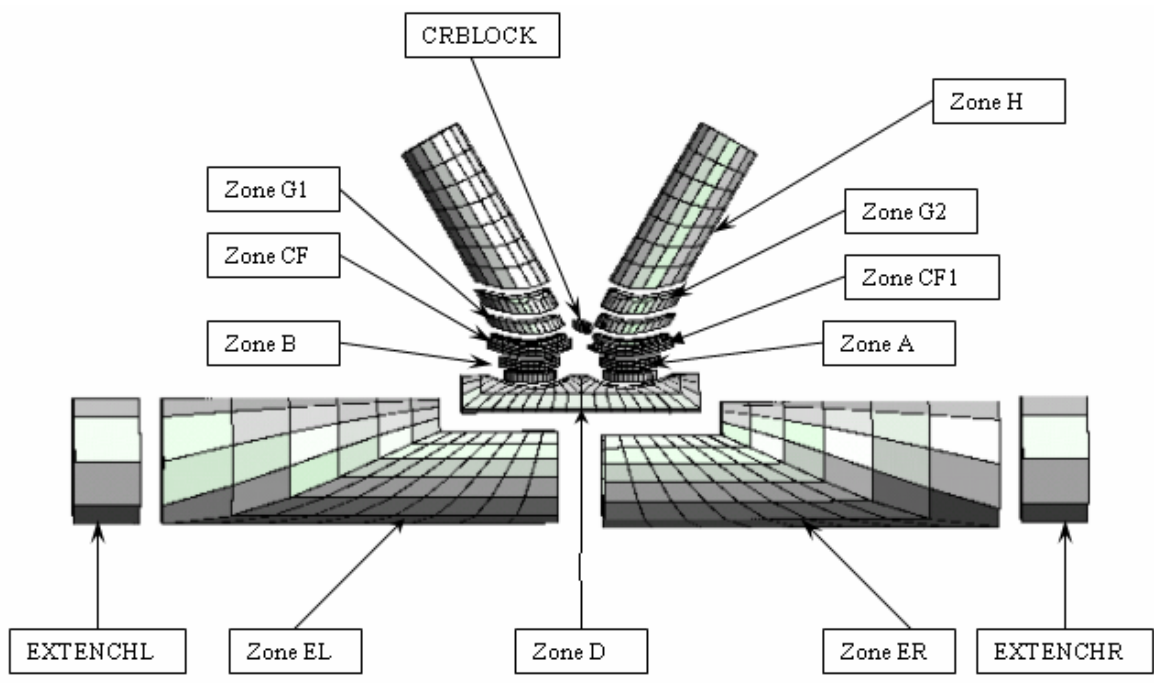

Figure 8. Mesh Generation of the Tubular K-joint

Figure 9 shows the mesh of CRBLOCK in a detailed view. CRBLOCK is extracted from Zone CF1. It should be emphasized that the number and location of elements extracted from Zone CF1 will depend on the crack length and position. Once the crack length and the crack position are determined, the number of elements to be extracted will be calculated automatically. Therefore, a surface crack with any length at any fixed position can be generated automatically.

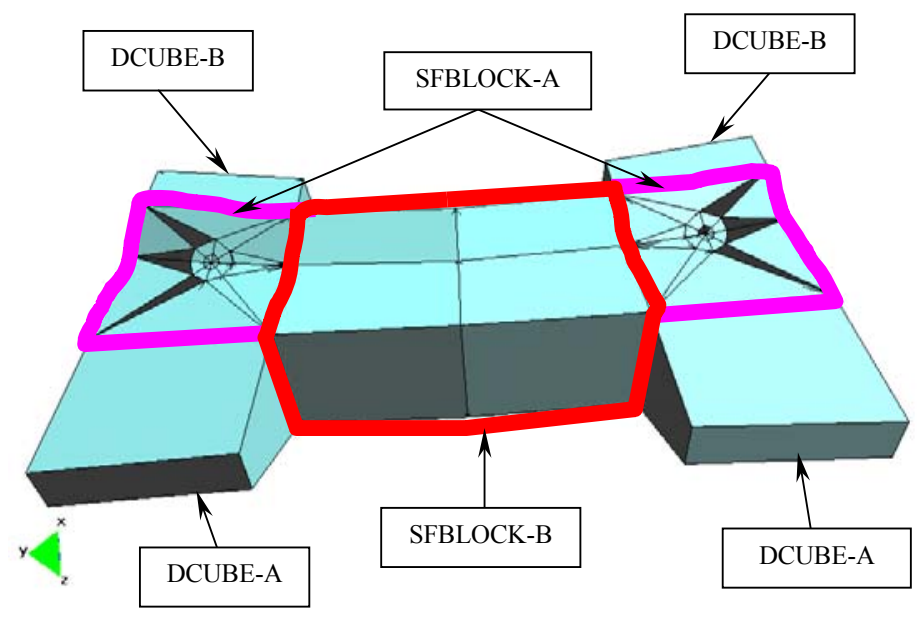

Figure 9. CRBLOCK Extracted from Zone CF1 and Zone D

After extracting CRBLOCK from Zone CF1, all the elements used in Zone CF1 are hexahedral elements since no crack in this zone. The mesh in details of Zone CF1 after extracting CRBLOCK is shown in Figure 10. 


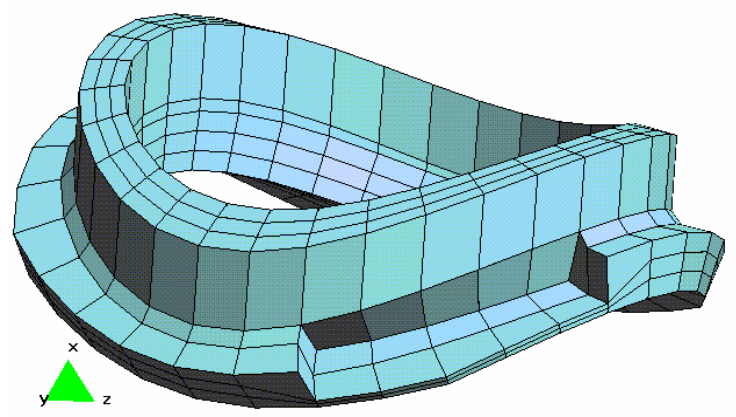

Figure 10. Mesh of Zone CF1 After Extracting CRBLOCK

After the mesh of all the zones has been completed, they are then merged together to form the mesh of the entire structure. Figure 11 shows the mesh of a K-joint after merging the mesh of all the zones.

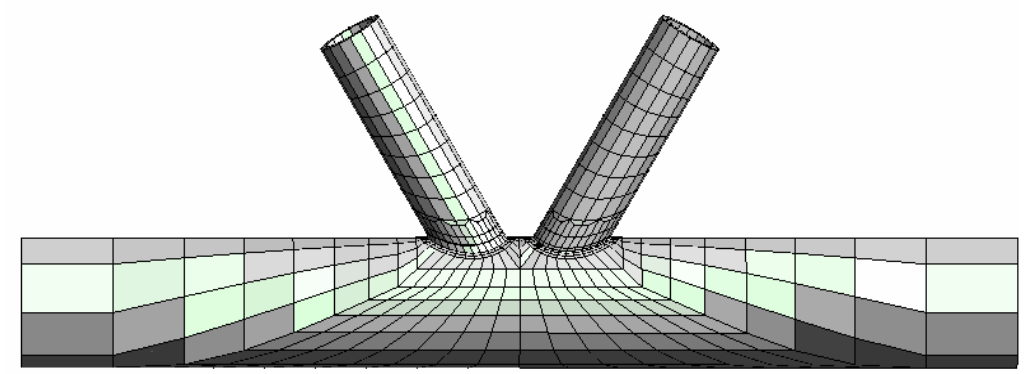

Figure 11. Mesh of Tubular K-joint After Merging All the Zones

According to the joint dimensions and the 3D crack size, a finite element model shown in Figure 12 is generated automatically (Lie at al. [7]) to calculate the stress intensity factors at the critical locations, namely, at the deepest point and at the crack tips. The K-joint specimen is subjected with an axial load (AX) of $150 \mathrm{kN}$ and an in-plane bending (IPB) of $38 \mathrm{kNm}(13.5 \mathrm{kN} \times 2.815 \mathrm{~m})$ respectively.

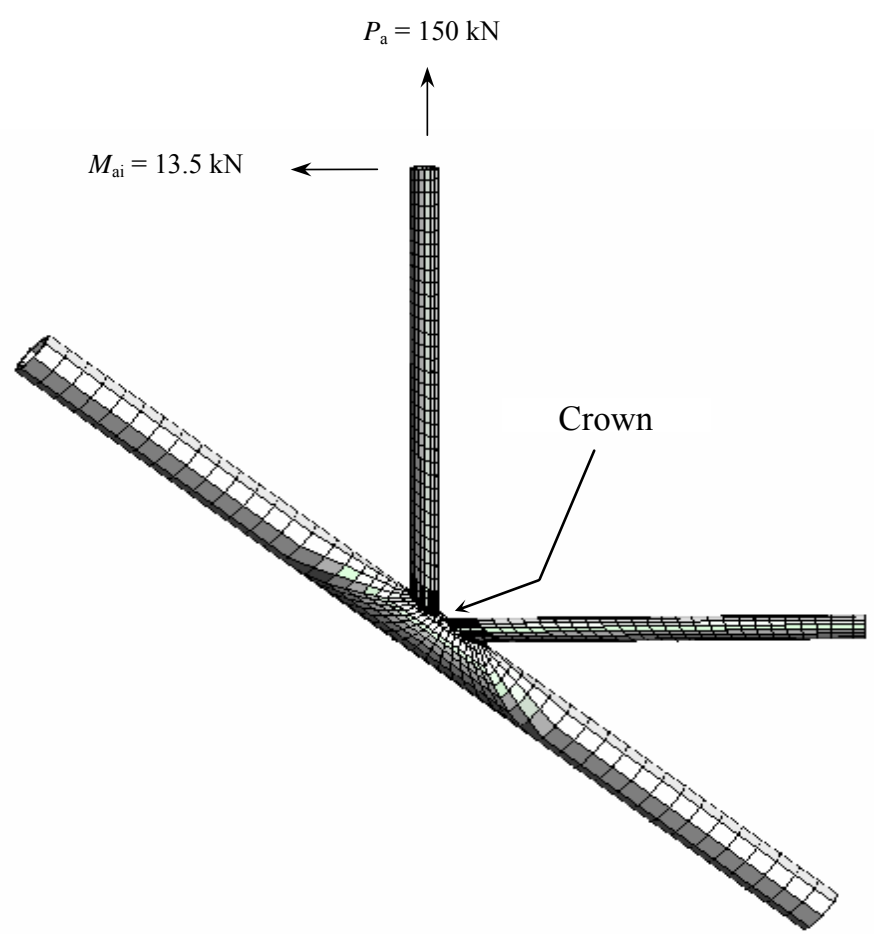

Figure 12. Finite Element Mesh and Loading Conditions 


\subsection{Stress Intensity Factors}

To estimate the remaining life of tubular K-joints, the fracture parameter called the stress intensity factor (SIF) is frequently used by many researchers. There are several methods which can be used to evaluate this fracture parameter. In practice, the two most commonly used methods are the $J$-integral and the displacement extrapolation. The $J$-integral has been found to be insensitive to mesh refinement, but it can not be used directly in the mixed mode problems. However, the Mode-I, II \& III SIFs can still be obtained from the $J$-integral using an indirect way by introducing an interaction integral method (Shih and Asaro [13]). It is also noted that $J$-integral lacks path independence in the region where the crack meets the weld toe because the stress at the toe and the crack tip is singular. On the other hand, displacement extrapolation method is based on Westergaard's equations which relate the displacements in the vicinity of the crack front to the stress intensity factors. This method is not applicable for inelastic behaviour.

\subsubsection{J-integral method}

$J$-integral method is then used to obtain the stress intensity factors along the crack front and at the two crack tips. Although this method can not be used directly for the mixed mode problems, it can still be able to produce the Mode-I, II \& III stress intensity factors through an indirect way by introducing an interaction integral method as proposed by Shih and Asaro [13]. The relationship between the $J$-integral and the SIFs can be written as

$$
\mathbf{J}=\frac{1}{8 \pi} \mathbf{K}^{\mathbf{T}} \cdot \mathbf{B} \cdot \mathbf{K}
$$

where $\mathbf{K}=\left[K_{\mathrm{I}}, K_{\mathrm{II}}, K_{\mathrm{III}}\right]^{\mathbf{T}}$ and $\mathbf{B}$ is called the pre-logarithmic energy factor matrix.

Shih and Asaro [13] gave the relationship between the SIF and the interaction $J$-integral, $\mathbf{J}_{\text {int }}$, as follow:

$\mathbf{K}=4 \pi \mathbf{B} \cdot \mathbf{J}_{\text {int }}$

where $\mathbf{J}_{\text {int }}=\left[J_{\text {int }}^{\mathrm{I}}, J_{\text {int }}^{\mathrm{II}}, J_{\text {int }}^{\mathrm{III}}\right]^{\mathbf{T}}$.

Therefore, once $\mathbf{J}_{\text {int }}$ is obtained, $\mathbf{K}$ can be easily calculated from Eq. 10. The detailed calculations of $\mathbf{J}_{\text {int }}$ can be found in the paper published by Shih and Asaro [13], and this method has been implemented in the ABAQUS [14] general finite element software. The values of Mode-I stress intensity factors $K_{\mathrm{I}}$ corresponding to the crack depth $a$ and crack length $2 c$ at the deepest point and the crack tips are tabulated in Tables 2 and 3 respectively.

\section{ASSESSMENT POINTS OF $K_{\mathrm{r}}$ AND $L_{\mathrm{r}}$}

In order to assess the safety and integrity of this cracked tubular K-joint subjected under the combined loads, BS7910 [1] Level 2A failure assessment diagram (FAD) method is employed in this study. FADs are used to consider failure by linear elastic fractures as one limiting criteria and failure by plastic collapse as the second criteria. When performing a structural integrity assessment of a flaw in a stressed structure, an assessment point is derived from two different calculations and 
plotted on the diagram. The structure is deemed unsafe if the point calculated lies on the curve or falls outside it, and it is safe if the point is within the curve.

For offshore tubular joints, the plastic collapse loads for the cracked geometry $P_{\mathrm{c}}$ are determined by multiplying the plastic collapse loads for the corresponding uncracked geometry $P_{\text {uncracked }}$ with the reduction factor $F_{\mathrm{AR}}$. The plastic collapse loads of uncracked K-joint $P_{\text {uncracked }}$ can be obtained from the Health and Safety Executive (HSE) [10], and the correction factors $F_{\mathrm{AR}}$ for axial load and in-plane bending are given by Eqs. 6 and 7 respectively.

The brace and chord members were fabricated from standard API 5L Grade B specifications pipes, and the fracture toughness measured at room temperature is approximately $147 \mathrm{MPa} \cdot \mathrm{m}^{1 / 2}$ (Somerday [15]). Because the material exhibits significant strain-hardening, the flow stress $\sigma_{\mathrm{F}}$ will be used and it is given by

$\sigma_{\mathrm{F}}=\frac{\sigma_{\mathrm{Y}}+\sigma_{\mathrm{u}}}{2}$

to obtain the $L_{\mathrm{r}}$ parameter. From the standard coupon tests, the measured yield stress $\sigma_{\mathrm{Y}}=352 \mathrm{MPa}$ and $\sigma_{\mathrm{u}}=493 \mathrm{MPa}$ respectively.

Then, the corresponding values of $K_{\mathrm{r}}$ and $L_{\mathrm{r}}$ for different crack sizes can be computed and they are tabulated in Table 2 at the deepest points and Table 3 at the crack tips subsequently. The assessment points of this cracked K-joint are plotted in the assessment curve shown in Figures 13 and 14 respectively. For the surface cracks in the K-joint, the maximum crack driving force (SIFs or CTOD) seems to be at the crack tips. Therefore, the SIFs or CTOD at this point should be used to calculate the $K_{\mathrm{r}}$ values.

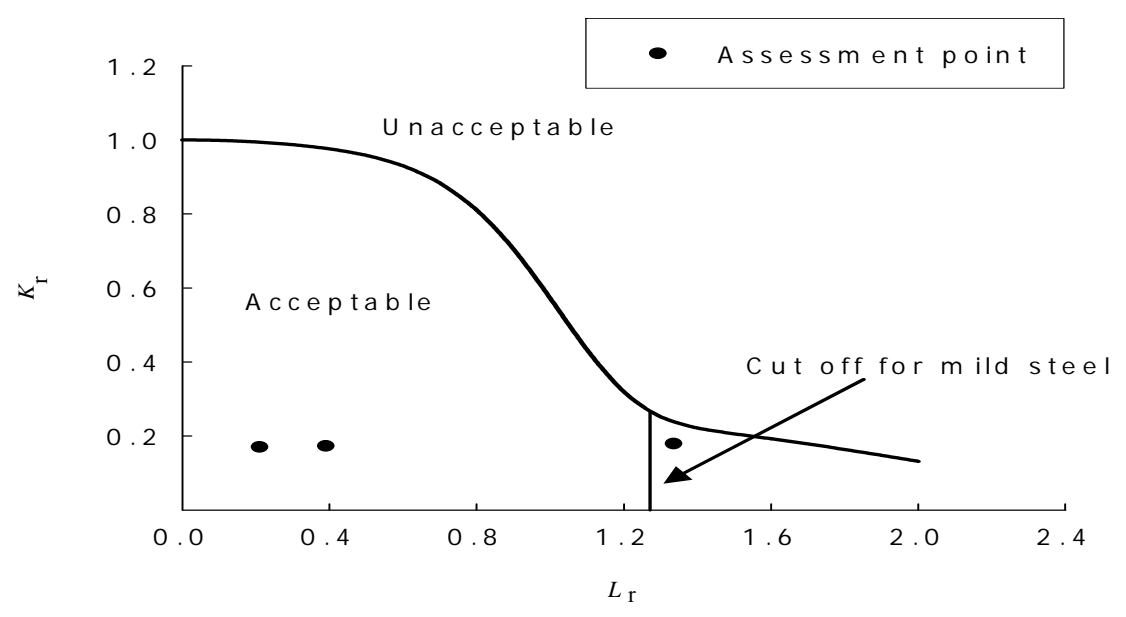

Figure 13. Plot of Assessment Points at the Deepest Points 


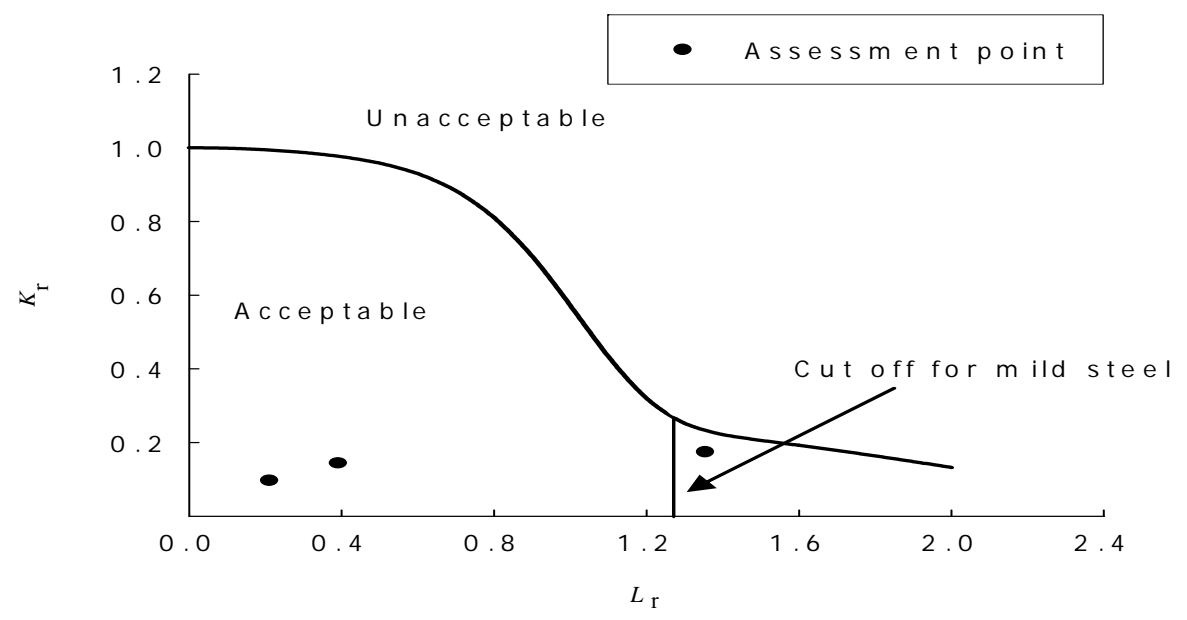

Figure 14. Plot of Assessment Points at the Crack Tips

Table 2. Calculated Values of $K_{\mathrm{r}}$ and $L_{\mathrm{r}}$ at the Deepest Points

\begin{tabular}{|c|c|c|c|c|c|c|}
\hline $\begin{array}{c}a \\
(\mathrm{~mm})\end{array}$ & $\begin{array}{c}a / T \\
(\mathrm{~mm})\end{array}$ & $\begin{array}{c}c \\
(\mathrm{~mm})\end{array}$ & $\begin{array}{c}2 c \\
(\mathrm{~mm})\end{array}$ & $\begin{array}{c}K_{\mathrm{I}} \\
{\mathrm{MPa} . \mathrm{m}^{1 / 2}}^{1 / 2}\end{array}$ & $\begin{array}{c}L_{\mathrm{r}} \\
K_{\mathrm{I}} / K_{\mathrm{IC}}\end{array}$ & $\begin{array}{c}K_{\mathrm{r}} \\
P / P_{\mathrm{c}}\end{array}$ \\
\hline 3.30 & 0.130 & 35.20 & 70.40 & 25.12 & 0.210 & 0.171 \\
\hline 5.33 & 0.210 & 44.82 & 89.64 & 25.51 & 0.390 & 0.173 \\
\hline 8.13 & 0.320 & 58.98 & 117.96 & 26.39 & 1.335 & 0.180 \\
\hline 10.41 & 0.410 & 66.12 & 132.24 & 28.21 & 2.988 & 0.192 \\
\hline 13.46 & 0.530 & 75.33 & 150.66 & 30.10 & 10.947 & 0.205 \\
\hline 15.75 & 0.620 & 82.67 & 165.34 & 30.94 & 41.518 & 0.210 \\
\hline 18.03 & 0.710 & 88.19 & 176.38 & 32.51 & 148.174 & 0.221 \\
\hline 20.83 & 0.820 & 95.89 & 191.78 & 35.42 & 1712.024 & 0.241 \\
\hline
\end{tabular}

Table 3. Calculated Values of $K_{\mathrm{r}}$ and $L_{\mathrm{r}}$ at the Crack Tips

\begin{tabular}{|c|c|c|c|c|c|c|}
\hline $\begin{array}{c}a \\
(\mathrm{~mm})\end{array}$ & $\begin{array}{c}a / T \\
(\mathrm{~mm})\end{array}$ & $\begin{array}{c}c \\
(\mathrm{~mm})\end{array}$ & $\begin{array}{c}2 c \\
(\mathrm{~mm})\end{array}$ & $\begin{array}{c}K_{\mathrm{I}} \\
\mathrm{MPa}^{1 / 2}\end{array}$ & $\begin{array}{c}L_{\mathrm{r}} \\
K_{\mathrm{I}} / K_{\mathrm{IC}}\end{array}$ & $\begin{array}{c}K_{\mathrm{r}} \\
P / P_{\mathrm{c}}\end{array}$ \\
\hline 3.30 & 0.130 & 35.20 & 70.40 & 14.34 & 0.210 & 0.098 \\
\hline 5.33 & 0.210 & 44.82 & 89.64 & 21.27 & 0.390 & 0.145 \\
\hline 8.13 & 0.320 & 58.98 & 117.96 & 25.73 & 1.353 & 0.175 \\
\hline 10.41 & 0.410 & 66.12 & 132.24 & 29.66 & 2.988 & 0.202 \\
\hline 13.46 & 0.530 & 75.33 & 150.66 & 36.50 & 10.947 & 0.248 \\
\hline 15.75 & 0.620 & 82.67 & 165.34 & 37.30 & 41.518 & 0.254 \\
\hline 18.03 & 0.710 & 88.19 & 176.38 & 35.80 & 148.174 & 0.244 \\
\hline 20.83 & 0.820 & 95.89 & 191.78 & 34.50 & 1712.024 & 0.235 \\
\hline
\end{tabular}

In accordance with the FADs shown in Figures 13 and 14, it can be seen that only three assessment points fall inside the standard Level 2A curve, i.e. for $a / T$ is less than 0.4 . Therefore, the critical load value is less than the crack initiation load value and the crack K-joint is still safe. When $a / T$ goes beyond 0.4 , it is noted that the $L_{\mathrm{r}}$ values are substantially larger, and therefore the cracked $\mathrm{K}$-joint is deemed to fail beyond this crack size. 
The increase of $K_{\mathrm{r}}$ is more gradual compared to the increase of $L_{\mathrm{r}}$ as the stress intensity factors, both at the deepest points and crack tips, do not increase drastically as the crack size increases. An increased load or larger crack size will move the assessment point along the loading path toward the failure line as shown in Figures 13 and 14. The reliability of the method depends on how accurately the intersection zone is described by the failure curve which depends on the structural geometry, type of loading and crack size.

\section{CONCLUSIONS}

This paper demonstrates the usage of BS7910 [1] to assess the safety and integrity of a typical cracked tubular CHS K-joint where failure is characterized by two criteria, namely, crack tip failure where failure occurs when the applied load equals the LEFM failure load, i.e.

$$
K_{\mathrm{r}}=\frac{K_{\mathrm{I}}}{K_{\mathrm{IC}}}=\frac{\text { load }}{\text { LEFM failure load }}=1
$$

and failure by plastic collapse of the ligament given by

$$
L_{\mathrm{r}}=\frac{P}{P_{\mathrm{c}}}=\frac{\text { load }}{\text { ligament area } \times \sigma_{\mathrm{F}}}=1
$$

where $\sigma_{\mathrm{F}}$ is the material flow stress.

This approach enables the integrity of cracked circular hollow section (CHS) tubular joints to be assessed through two separate calculations based on the two extremes of fracture behaviour, linear elastic and fully plastic. A design curve is used to interpolate between the two failure criteria. The relative position of the assessment point on the diagram, derived from the two separate calculations, determines the integrity of the structure. If the assessment point falls inside the failure curve, the structure is deemed safe; if the assessment point is on or outside the curve, then failure is predicted to occur. For the cracked K-joint considered, it is found that only three assessment points fall inside the standard Level 2A curve, and hence this damaged joint is still safe if $a / T$ is less than 0.4 operating under the specified conditions.

\section{NOMENCLATURE}

$$
\begin{array}{ll}
a & =\text { crack depth of surface crack } \\
\mathbf{B} & =\text { pre-logarithmic energy factor matrix } \\
d & =\text { brace diameter } \\
D & =\text { chord diameter } \\
E & =\text { Young's modulus } \\
F_{\mathrm{AR}} & =\text { correction factor } \\
g & =\text { gap distance between two braces } \\
J_{\mathrm{e}} & =\text { value of } J \text { determined using an elastic analysis } \\
J_{\text {ep }} & =\text { value of } J \text { determined using an elastic-plastic analysis } \\
\mathbf{J} & =J \text {-integral matrix of }\left[J_{\mathrm{I}}, J_{\mathrm{II}}, J_{\mathrm{III}}\right]^{\mathbf{T}} \\
\mathbf{J}_{\text {int }} & =J \text {-integral matrix of }\left[J_{\text {int }}^{\mathrm{I}}, J_{\text {int }}^{\mathrm{II}}, J_{\text {int }}^{\mathrm{III}}\right]^{\mathbf{T}}
\end{array}
$$


$K_{\mathrm{I}}=$ Mode-I stress intensity factor

$K_{\mathrm{II}} \quad=$ Mode-II stress intensity factor

$K_{\mathrm{III}} \quad=$ Mode-III stress intensity factor

$K_{\text {eff }}=$ effective stress intensity factor

$K_{\mathrm{IC}}=$ fracture toughness

$K_{\mathrm{r}}=$ ratio of elastic stress intensity factor to fracture toughness

$\mathbf{K}=$ stress intensity factor matrix of $\left[K_{\mathrm{I}}, K_{\mathrm{II}}, K_{\mathrm{III}}\right]^{\mathbf{T}}$

$L=$ half chord length

$L_{\mathrm{r}} \quad=\quad$ ratio of applied load to plastic collapse load

$m_{\mathrm{q}}=$ a factor equal to 1.0 for circular hollow section (CHS) tubular joints

$M_{\mathrm{ai}} \quad=$ applied in-plane bending

$M_{\text {ao }} \quad=$ applied out-of-plane bending

$M_{\mathrm{ci}} \quad=\quad$ in-plane bending plastic collapse

$M_{\mathrm{co}} \quad=$ out-of-plane bending plastic collapse

$P \quad=$ total applied load

$P_{\mathrm{a}} \quad=$ applied axial load

$P_{\mathrm{c}} \quad=$ plastic collapse load

$P_{\text {uncracked }}=$ plastic collapse load of the uncracked joint

$Q_{\beta}=$ a factor equal to 1.0 for $\beta \leq 1.0$

$t \quad=$ brace thickness

$T=$ chord thickness

$\alpha=$ ratio of twice chord length to chord diameter

$\beta=$ ratio of brace to chord diameter

$\gamma=$ ratio of brace diameter to twice chord thickness

$\varepsilon_{\text {ref }} \quad=$ reference strain

$\varsigma=$ ratio of gap distance of two braces to chord diameter

$\theta_{1}, \theta_{2}=$ brace to chord angles

$v=$ Poisson's ratio

$\sigma^{\mathrm{P}} \quad=$ total applied stress

$\sigma_{\mathrm{F}} \quad=$ flow stress of the material

$\sigma_{\mathrm{u}}=$ ultimate stress of the material

$\sigma_{\mathrm{Y}}=$ yield stress of the material

$\tau=$ ratio of brace thickness to chord thickness

$\varphi=$ extended angle of surface crack 


\section{REFERENCES}

[1] BS7910, "Guide to Methods for Assessing the Acceptability of Flaws in Fusion Welded Structures", British Standards Institution, London, UK, 2005.

[2] API RP579, "Fitness-for-Service", American Petroleum Institute, Washington, USA, 2000.

[3] CEGB R6, "Assessment of the Integrity of Structures Containing Defects", Revision 4, British Energy, Gloucester, UK, 2001.

[4] Dowling, A.B. and Townley, C.H.A., "The Effect of Defect on Structural Failure: A Two-Criteria Approach", International Journal of Pressure Vessels and Piping, 1975, Vol. 3, No. 2, pp. 77-107.

[5] Wiesner, C.S., Maddox, S.J., Xu, W., Webster, G.A., Burdekin, F.M., Andrews, R.M. and Harrison, J.D., "Engineering Critical Analyses to BS7910 - the UK Guide on Methods for Assessing the Acceptability of Flaws in Metallic Structures", International Journal of Pressure Vessels and Piping, 2000, Vol. 77, No. 14-15, pp. 883-893.

[6] Dawes, M.G. and Denys, R., "BS 5500 Appendix D: An Assessment Based on Wide Plate Brittle Fracture Test Data", International Journal of Pressure Vessels and Pipings, 1984, Vol. 15, pp. 161-192.

[7] Lie, S.T., Lee, C.K., Chiew S.P. and Shao, Y.B., "Mesh Modelling and Analysis of Cracked Uni-planar Tubular K-joints", Journal of Constructional Steel Research, 2005, Vol. 61, No. 2, pp. 235-264.

[8] BS7448-1, "Fracture Mechanics Toughness Tests - Part 1: Method for Determination of $K_{\text {IC }}$, Critical CTOD and Critical J Values of Metallic Structures", British Standards Institution, London, UK, 1991.

[9] Lie, S.T., Lee, C.K., Chiew, S.P. and Shao, Y.B., "Estimation of Stress Intensity Factors of Weld Toe Surface Cracks in Tubular K-joints", Proceedings of the 10th International Symposium on Tubular Structures, Madrid, Spain, 2003, pp. 347-355.

[10] Health and Safety Executive (HSE), "Offshore Installation: Guidance on Design, Construction and Certification", 4th Edition, Third Amendment, Her Majesty's Stationary Office, London, UK, 1995.

[11] Lie S.T., Chiew S.P., Lee C.K. and Shao, Y.B., "Validation of a Surface Crack Stress Intensity Factors of a Tubular K-joint", International Journal of Pressure Vessels and Piping, 2005, Vol. 82, No. 8, pp. 610-617.

[12] Dover, W.D., Dharmavasan, S., Brennan, F.P. and Marsh, K.J., "Fatigue Crack Growth in Offshore Structures”, Engineering Materials Advisory Services (EMAS) Ltd., Chameleon Press, London, UK, 1995.

[13] Shih, C.F. and Asaro, R.J., "Elastic -Plastic Analysis of Cracks on Bimaterial Interface: Part I-Small Scale Yielding", Journal of Applied Mechanics, ASME, 1998, Vol. 51, pp. 299-316.

[14] ABAQUS, “User's Manual”, Version 6.5, Hibbit, Karlsson and Sorensen Inc., Providence, USA, 2005.

[15] Somerday, B.P., "Technical Reference on Hydrogen Compatibility of Materials - Carbon Steel: C-Mn Alloys (Code 1100)", Sandia National Laboratory, Livermore, California, USA, 2007. 